\title{
Risk-Reducing Mastectomy for BRCA Gene Mutation Carriers
}

\author{
David M. Euhus \\ Johns Hopkins Hospital, Baltimore, MD
}

A family history of early-onset breast cancer in multiple relatives is an important breast cancer risk factor that should prompt efforts to define and manage cancer risk. Genetic testing is the most powerful tool we have for precisely determining who in these families is at increased risk and who is not. With the advent of massive parallel sequencing or next-generation sequencing and the commercialization of multigene panels, we have incrementally expanded the proportion of families that can be understood and managed from a genetic perspective. Nevertheless, BRCA1 and BRCA2 remain the most commonly identified genes affected by deleterious mutations. The next largest fraction includes PALB2, CHEK2, and ATM, but it is estimated that even with whole-genome sequencing, we are explaining only about $35 \%$ of apparent inherited breast cancer predisposition. ${ }^{1}$

The first task after receiving a "deleterious" or "likely deleterious" genetic test result is to estimate cancer risks. This requires knowledge about the mutated gene, about the specific mutation, and about the extended cancer family history. It is common, but not accurate, to see a BRCA1 mutation and immediately assume that the lifetime breast cancer risk is $80 \%$. Slight differences in the way we code for other genes (polymorphisms) can influence the cancer probabilities associated with mutations in major predisposition genes. Different families have different risk profiles, even with the same mutation. This has been observed for BRCA1 for which lifetime breast cancer risk has been estimated at 26-87\% depending on the associated family history. It also is true for the newer "modest penetrance" genes such as ATM, for which the lifetime risk appears to be as high as $60 \%$ in some families. ${ }^{2}$ Attention to the

(C) Society of Surgical Oncology 2015

First Received: 15 March 2015;

Published Online: 28 March 2015

D. M. Euhus

e-mail: deuhus1@jhmi.edu three-generation cancer family history during post-test counseling cannot be emphasized enough.

Once cancer risks have been estimated, the focus shifts to developing a risk management strategy that considers the magnitude of the risk, the risks and effectiveness of possible interventions, and individual risk tolerance and preferences. The options to consider include lifestyle interventions, enhanced surveillance, chemoprevention, and risk-reducing surgery.

The meta-analysis by De Felice and colleagues reported in this Annals of Surgical Oncology issue contributes to this discussion by attempting to quantify the breast cancer risk reduction afforded by bilateral risk-reducing mastectomy for BRCA gene mutation carriers. Their analysis included four prospective studies and estimated a $93 \%$ reduction in breast cancer risk. Is this the number we should quote to our BRCA gene mutation carriers? A careful look at the studies included (or excluded) in this analysis will help to calibrate our confidence in the result.

De Felice and colleagues were interested in prospective English-language studies describing bilateral prophylactic mastectomy in BRCA1 and BRCA2 mutation carriers with no diagnosis of breast cancer by the time of mastectomy. They tried to avoid including separate publications that reported many of the same patients but admit that they may not have been entirely successful in doing this. Ultimately, they selected four studies that included 627 risk-reducing mastectomy patients. They included the initial Rotterdam Cancer Family Clinic study and the extended Rotterdam series, with a longer follow-up period for this same group. Up to 76 women may have been counted twice. They included the most recent Prevention and Observation of Surgical Endpoints (PROSE) study, which reported no breast cancers among 247 BRCA gene mutation carriers followed for a median of 3.7 years after prophylactic mastectomy, but excluded the initial PROSE study that diagnosed two breast cancers among 107 women followed for a median of 6.4 years. Presumably this study was 
excluded because it combined both prospective and retrospective cohorts. No breast cancers were observed in the prospective cohort, but the retrospective cohort had two cases. Only four postmastectomy breast cancers were described in the four included studies: one from the extended follow-up Rotterdam study and three from the Danish Multicenter Study. The fact that only 4 of 627 women undergoing risk-reducing mastectomy had a diagnosis of breast cancer could be encouraging, but the median followup period for all the included studies was only about 4 years.

Several reports describe nodal or distant metastases from an unknown primary after risk-reducing mastectomy, but most postmastectomy breast cancers occur in residual breast tissue. The three primary breast cancers from the 96 risk-reducing mastectomies included in the Danish Multicenter Study all occurred in BRCA1 mutation carriers. The authors note that risk-reducing mastectomies were not performed in units dedicated to the management of BRCA gene mutation carriers, which is consistent with practice in the United States. They estimated the postmastectomy breast cancer risk to be $0.8 \%$ per year.

It is not clear what the absolute breast cancer risk will be 10,20 , or 30 years after risk-reducing mastectomy in BRCA gene mutation carriers. However, these are young women with decades of living ahead of them. Mastectomy should be meticulous and thorough while minimizing the impact on body image. Breast cancer risk cannot be eliminated completely because short of removing all the skin of the breast envelope, it is not possible to remove all the breast epithelium in every woman. After mastectomy, terminal duct-lobular units (TDLU) can be identified in peripheral skin in $22-60 \%,{ }^{3-5}$ in the inframammary fold in $54 \%,{ }^{6}$ and in the nipple-areolar complex in $9-61 \%$ of patients. $^{7-9}$

Removing the nipple-areolar complex incrementally reduces the number of residual TDLU's, but it is not clear that this is required to achieve an acceptably low breast cancer risk. It is reassuring that the large Mayo Clinic series of mostly nipple-sparing subcutaneous mastectomies in familial high-risk women showed more than a $90 \%$ reduction in breast cancer risk. ${ }^{10}$ Only 26 of these women were confirmed to carry BRCA gene mutations (18 deleterious and 8 uncertain). No breast cancers developed in these women during a median follow-up period of 13.4 years. ${ }^{11}$

It is currently uncertain whether bilateral risk-reducing mastectomy improves either breast cancer-specific or overall survival in BRCA gene mutation carriers. Modeling studies predict that this will be observed in time, ${ }^{12,13}$ and a 2010 Cochrane review concludes that risk-reducing mastectomy is likely to confer a survival advantage in the highest-risk women. ${ }^{14}$ Bilateral oophorectomy reduces breast cancer risk by $37-72 \%$ and likely improves breast cancer-specific and overall survival in BRCA gene mutation carriers. ${ }^{15}$ The current meta-analysis by De Felice and colleagues suggests that the addition of oophorectomy to mastectomy is neither additive nor synergistic for breast cancer risk reduction.

Only $18-40 \%$ of BRCA gene mutation carriers opt for risk-reducing mastectomy, and this figure varies greatly by country. ${ }^{16-18}$ Improved surgical techniques, including reconstruction, may have contributed to the $12 \%$ per year increase in bilateral prophylactic mastectomy observed in the United States during the last decade. ${ }^{19}$ Bilateral prophylactic mastectomy with reconstruction is a major surgical procedure, and although some have reported very low complication rates, ${ }^{20}$ the bulk of available data suggest that $8-64 \%$ of women will experience one or more complications $^{21-24}$ and that $52-71 \%$ will require reoperation. ${ }^{24-26}$

Prophylactic mastectomy also has a significant impact on body image and psychosocial function. One study found that even after completion of reconstruction, $37 \%$ of women reported that their breasts felt unpleasant, $29 \%$ were not satisfied with their breast appearance, and $21 \%$ felt embarrassed for their naked bodies. ${ }^{27}$ In addition, breast stimulation is an important component of sexual arousal for some women that is severely impaired or lost altogether after mastectomy. ${ }^{28}$

In summary, bilateral risk-reducing mastectomy significantly reduces near-term breast cancer risk in BRCA gene mutation carriers. The median follow-up period for the largest studies is only about 4 years, so durability is uncertain. To date, no worrisome signals are portending accelerated breast cancer rates over time. A technically thorough mastectomy seems advisable, but this does not preclude a nipple-sparing approach. Mastectomy is one risk-management option for BRCA gene mutation carriers. Complications, reoperation, and potentially negative impacts on psychosocial and physical functioning require careful preoperative counseling and individualized, patientdriven decisions.

\section{REFERENCES}

1. Gracia-Aznarez FJ, Fernandez V, Pita G, et al. Whole-exome sequencing suggests much of non-BRCA1/BRCA2 familial breast cancer is due to moderate and low penetrance susceptibility alleles. PloS One. 2013;8:e55681.

2. Goldgar DE, Healey S, Dowty JG, et al. Rare variants in the ATM gene and risk of breast cancer. BCR Breast Cancer Res. 2011;13:R73.

3. Torresan RZ, dos Santos CC, Okamura H, et al. Evaluation of residual glandular tissue after skin-sparing mastectomies. Ann Surg Oncol. 2005;12:1037-44.

4. Barton FE Jr, English JM, Kingsley WB, et al. Glandular excision in total glandular mastectomy and modified radical mastectomy: 
a comparison. Plast Reconstr Surg. 1991;88:389-92; discussion 393-384.

5. Tewari M, Kumar K, Kumar M, et al. Residual breast tissue in the skin flaps after Patey mastectomy. Indian $J$ Med Res. 2004;119:195-7.

6. Carlson GW, Grossl N, Lewis MM, et al. Preservation of the inframammary fold: what are we leaving behind? Plast Reconstr Surg. 1996;98:447-50.

7. Kryvenko ON, Yoon JY, Chitale DA, et al. Prevalence of terminal duct lobular units and frequency of neoplastic involvement of the nipple in mastectomy. Arch Pathol Lab Med. 2013; 137:955-60.

8. Reynolds C, Davidson JA, Lindor NM, et al. Prophylactic and therapeutic mastectomy in BRCA mutation carriers: can the nipple be preserved? Ann Surg Oncol. 2011;18:3102-9.

9. van Verschuer VM, van Deurzen $\mathrm{CH}$, Westenend PJ, et al. Prophylactic nipple-sparing mastectomy leaves more terminal duct lobular units in situ as compared with skin-sparing mastectomy. Am J Surg Pathol. 2014;38:706-12.

10. Hartmann LC, Schaid DJ, Woods JE, et al. Efficacy of bilateral prophylactic mastectomy in women with a family history of breast cancer. $N$ Engl J Med. 1999;340:77-84.

11. Hartmann LC, Sellers TA, Schaid DJ, et al. Efficacy of bilateral prophylactic mastectomy in BRCA1 and BRCA2 gene mutation carriers. J Nat Cancer Inst. 2001;93:1633-7.

12. Kurian AW, Sigal BM, Plevritis SK. Survival analysis of cancer risk reduction strategies for BRCA1/2 mutation carriers. J Clin Oncol. 2010;28:222-31.

13. Sigal BM, Munoz DF, Kurian AW, et al. A simulation model to predict the impact of prophylactic surgery and screening on the life expectancy of BRCA1 and BRCA2 mutation carriers. Cancer Epidemiol Biomark Prev. 2012;21:1066-77.

14. Lostumbo L, Carbine NE, Wallace J. Prophylactic mastectomy for the prevention of breast cancer. Cochrane Database Syst Rev. 2010;11:CD002748.

15. Domchek SM, Friebel TM, Singer CF, et al. Association of riskreducing surgery in BRCA1 or BRCA2 mutation carriers with cancer risk and mortality. JAMA. 2010;304:967-75.

16. Metcalfe KA, Birenbaum-Carmeli D, Lubinski J, et al. International variation in rates of uptake of preventive options in BRCA1 and BRCA2 mutation carriers. Int $J$ Cancer. 2008;122:2017-22.

17. Beattie MS, Crawford B, Lin F, et al. Uptake, time course, and predictors of risk-reducing surgeries in BRCA carriers. Genet Test Mol Biomarkers. 2009;13:51-6.
18. Evans DG, Lalloo F, Ashcroft L, et al. Uptake of risk-reducing surgery in unaffected women at high risk of breast and ovarian cancer is risk, age, and time dependent. Cancer Epidemiol Biomarkers Prev. 2009;18(8):2318-24.

19. Cemal Y, Albornoz CR, Disa JJ, et al. A paradigm shift in U.S. breast reconstruction: Part 2. The influence of changing mastectomy patterns on reconstructive rate and method. Plast Reconstr Surg. 2013;131:320e-6e.

20. Del Corral GA, Wes AM, Fischer JP, et al. Outcomes and cost analysis in high-risk patients undergoing simultaneous free flap breast reconstruction and gynecologic procedures. Ann Plast Surg. 2014. doi:10.1097/SAP.0000000000000156.

21. Goldflam K, Hunt KK, Gershenwald JE, et al. Contralateral prophylactic mastectomy: predictors of significant histologic findings. Cancer. 2004;101:1977-86.

22. Crosby MA, Garvey PB, Selber JC, et al. Reconstructive outcomes in patients undergoing contralateral prophylactic mastectomy. Plast Reconstr Surg. 2011;128:1025-33.

23. Barton MB, West CN, Liu IL, et al. Complications following bilateral prophylactic mastectomy. J Natl Cancer Inst Monogr. 2005;35:61-6.

24. Heemskerk-Gerritsen BA, Brekelmans CT, Menke-Pluymers $\mathrm{MB}$, et al. Prophylactic mastectomy in BRCA1/2 mutation carriers and women at risk of hereditary breast cancer: long-term experiences at the Rotterdam Family Cancer Clinic. Ann Surg Oncol. 2007;14:3335-44.

25. Arver B, Isaksson K, Atterhem H, et al. Bilateral prophylactic mastectomy in Swedish women at high risk of breast cancer: a national survey. Ann Surg. 2011;253:1147-54.

26. Zion SM, Slezak JM, Sellers TA, et al. Reoperations after prophylactic mastectomy with or without implant reconstruction. Cancer. 2003;98:2152-60.

27. Gopie JP, Mureau MA, Seynaeve C, et al. Body image issues after bilateral prophylactic mastectomy with breast reconstruction in healthy women at risk for hereditary breast cancer. Fam Cancer. 2013;12:479-87.

28. Gahm J, Hansson P, Brandberg Y, et al. Breast sensibility after bilateral risk-reducing mastectomy and immediate breast reconstruction: a prospective study. JPRAS J Plast Reconstr Aesth Surg. 2013;66(11):1521-7. 